\title{
Modified Acetal Approach to 157nm Resist Design
}

\author{
Sanjay Malik, Stephanie Dilocker, Jeff Eisele, Binod De, Murrae Bowden, Scott Scales, John \\ Hatfield, Andrew Blakeney and Plamen Tzviatkov \\ Arch Microelectronic Materials, 200 Massasoit Avenue, East Providence, RI 02914, USA \\ Tadayoshi Kokubo \\ FUJIFILM ARCH Co. Ltd, 4000 Kawashiri Yoshida-Cho, Haibara-Gun Shizuoka, Japan
}

\begin{abstract}
Optical absorbance data on a variety of acetal-derivatized hydroxystyrene based polymers are reported at $157 \mathrm{~nm}$. Acetals based on tertiary butyl, cyclohexyl ethyl and a silicon-derivative show improved transparency of the corresponding polymers compared with the parent hydroxystyrene backbone. Silicon-acetal demonstrated capability to resolve $80 \mathrm{~nm}$ dense trenches in a bilayer resist system. No silicon outgassing was observed upon $157 \mathrm{~nm}$ exposure. The resist also displayed excellent $\mathrm{O}_{2} / \mathrm{SO}_{2}$-etch properties.
\end{abstract}

Key words: bulky acetal, chemical amplification, $157 \mathrm{~nm}$, out-gassing, optical density

\section{Introduction}

Progress over the past couple of years in resist materials, fluorine laser technology and lens materials aimed at $157 \mathrm{~nm}$ lithography has resulted in the emergence of this technology as the preferred option for fabricating $70 \mathrm{~nm}$ devices, which are expected to be in manufacture by 2005 [1]. Improvements are still required, however, especially in resist materials, where the key challenge has been the development of polymer backbones with sufficient transparency to permit a resist thickness consistent with the demands of plasma etching. The problem is that virtually allorganic materials absorb strongly at $157 \mathrm{~nm}$ [2-5], limiting definitive selection of a viable materials platform. Commercial phenolic-based deep-UV resists, for example, show molar absorbances of the order of $7-8 \mu \mathrm{m}^{-1}$ at $157 \mathrm{~nm}$ compared with approx. $0.5 \mu \mathrm{m}^{-1}$ at $248 \mathrm{~nm}$. Optical densities of approx. 0.4 are required for vertical sidewall imaging, so acceptable imaging at $157 \mathrm{~nm}$ would require the thickness of a $248 \mathrm{~nm}$ resist to be reduced below $65 \mathrm{~nm}$. Exposing the resist at this thickness may be adequate for evaluating optical performance of the first generation of $157 \mathrm{~nm}$ exposure tools, but it is impractical in device manufacturing because of etch and defect concerns associated with such a thin film.

Early work at MIT had identified two materials platforms, with transparencies low enough to permit film thicknesses on the order of $200+\mathrm{nm}$. Specifically, fluoropolymers and polysiloxanes (including silsesquioxanes) were identified as potential materials platforms for $157 \mathrm{~nm}$ resists, and most research efforts have subsequently focused on these two systems.

Much work has been done on fluoropolymers as platforms for single layer resists, but these materials require addition of absorbing monomers to improve their etch resistance [6,7]. Siloxanes and silsesquioxanes, on the other hand, provide appropriate platforms for the imaging layer in a bilayer resist system. In these polymers, the silicon-containing unit is in the main chain as opposed to the side chain modifications typically found in $248 \mathrm{~nm}$ and $193 \mathrm{~nm}$ designs. The main chain polymers are transparent at $157 \mathrm{~nm}$ and have high silicon content, a prerequisite for efficient pattern transfer by $\mathrm{O}_{2}$ reactive-ion etching. Outgassing yields from irradiated polysiloxanes at $157 \mathrm{~nm}$ are reported to be low [4].

The structural modifications required to build a chemically-amplified resist from these compounds, invariably add to absorbance at $157 \mathrm{~nm}$. For example, Sooriyakumaran et al. [8] at IBM reported that the absorbance of a silsesquioxane polymer, functionalized with a fluorocarbinol group to promote aqueous-base solubility, was three to five times greater than that of the corresponding base resin.

Considerable effort has been devoted to taking conventional, moderately transparent, resist platforms and blocking groups, and modifying their absorption through appropriate 
fluorination of the polymer backbone [6,7, 9-12]. Recent spectroscopic studies [13] on the effect of the hexafluoroisopropanol (HFIP) group on the absorbance of polystyrene, for example, have shown that the absorbance of polystyrene is reduced from $6.6 \mu \mathrm{m}^{-1}$ to $3.44 \mu \mathrm{m}^{-1}$ for poly(4HFIPstyrene). A similar observation was also made by the IBM group at Almaden [3] who reported an absorbance of $3.2 \mu \mathrm{m}^{-1}$ for the HFIP derivatized polymer. This base-developable, fluoroalcohol group has been adopted by most research groups as the replacement for the phenols and carboxylates used at longer wavelengths, including analogous modified ESCAP formulations with HFIPstyrene $[3,14,15]$.

The blocking group must also be chosen carefully to minimize contribution to absorption at $157 \mathrm{~nm}$. Acetal groups do not absorb strongly at this wavelength and have been widely used. One problem with acetal groups, however, is their tendency to outgas during exposure, especially simple acetals based on low molecular weight alcohols. Our previous work on bulky acetal derivatized polyhydroxystyrene (PHS) showed that the level of out-gassing could be significantly reduced by appropriate choice of the blocking group [16,17].

In this paper, we extend the concept of bulky acetals to $157 \mathrm{~nm}$ resist design. We report results on a single layer resist design by employing nonsilicon containing acetal groups. We also report preliminary lithographic data on a siliconcontaining acetal in a bilayer resist system.

\section{Experimental}

\subsection{Materials.}

Hydroxystyrene based polymers and copolymers were either purchased, or synthesized in the lab following standard free radical polymerization procedures. The polymers were partially protected by acetal groups following known literature procedures.

\subsection{Characterization.}

Polymer compositions were determined by ${ }^{1} \mathrm{H}$ and ${ }^{13} \mathrm{C}$ NMR spectroscopy using a Bruker spectrometer Model Avance 400 operating at 400 $\mathrm{MHz}$. Molecular weights of the polymers were determined by GPC against polystyrene standards using an RI detector and a set of four styragel columns, The Millenium ${ }^{\mathrm{TM}}$ (v2.15) software package from Waters Corporation was used for data calculations

\subsection{Optical properties.}

The absorbance of polymer films was measured on an Acton VUV Spectrometer Model CAMS-507-PUV. The films were spin-coated onto 1-inch calcium fluoride disks and soft-baked at $120^{\circ} \mathrm{C}$ for 120 seconds to remove all solvent. Film thickness was measured using an n\&k tool, enabling normalization of the absorbance of each polymer.

\subsection{Lithographic properties:}

Photoresist formulations were prepared by blending the polymers with standardized amounts of a photo acid generator (PAG) and an organic amine in propylene glycol monomethyl ether acetate (PGMEA). Films were deposited by spin coating to a specified soft film thickness. The films were soft-baked at $120^{\circ} \mathrm{C}$ for 60 seconds and exposed to $157 \mathrm{~nm}$ wavelength using an Exitech exposure tool $(\mathrm{NA}=0.65 \sigma=0.3)$. The films were subjected to a post-exposure bake of $110^{\circ} \mathrm{C}$ for 60 seconds prior to development. The images were puddle developed for 45 seconds using an aqueous $0.262 \mathrm{~N}$ tetramethylammonium hydroxide solution.

\subsection{Etch properties:}

Bulk etch rates in an $\mathrm{O}_{2} / \mathrm{SO}_{2}$ plasma were determined using a LAM TCP 9400 reactive ion etcher. The change in resist film thickness was determined after etching for 60 seconds, enabling the bulk etch rate to be directly calculated. Resist films were spin-coated on silicon and soft baked at $130{ }^{\circ} \mathrm{C}$ for 90 seconds.

In experiments involving pattern transfer into the underlying substrate, line space patterns were first printed into $2350 \AA$ of imaging layer using an ASML/700 exposure tool (NA=0.63, $\sigma_{0} / \sigma_{i}=$ $0.80 / 0.50$ ). The photoresist film was deposited over a thermally-cured underlayer, and soft baked at $120{ }^{\circ} \mathrm{C}$ for 90 seconds to a specified film thickness. The underlayer was prepared by spincoating a film over silicon and baking it at $205^{\circ} \mathrm{C}$ for 90 seconds. Pattern transfer to the underlayer was achieved using an $\mathrm{O}_{2} / \mathrm{SO}_{2}$ etch in a LAM TCP 9400 reactive ion etcher. 


\section{Results and Discussion}

\subsection{Polymer composition and absorbance:}

Table 1 shows the absorbance of several polymer backbones together with the glass transition temperature $(\mathrm{Tg})$ of each material. The results show that the absorbance of PHS is reduced as HS is replaced with a fluorinated monomer, such as HFIPstyrene or hexafluoroisopropyl acrylate (HFIPA). For example, HS copolymers containing HFIPstyrene and HFIPA show $35 \%$ and $11 \%$ improvement respectively in optical density over PHS. The carbonyl-bond in the acrylate functionality is known to absorb strongly at $157 \mathrm{~nm}$, explaining the higher absorbance of HFIPA based homo- and copolymers compared with the corresponding HFIPstyrene-polymers. While the incorporation of HFIPA reduces the overall absorbance of PHS, the low $\mathrm{Tg}$ of poly(HFIPA) places a practical limit on the composition of the copolymer.

\section{Table 1}

Tg and Absorbance Values of Various Platforms at 157nm.

\begin{tabular}{|c|c|c|}
\hline Backbone Description & $\begin{array}{c}\text { Tg } \\
\left(^{\circ} \mathrm{C}\right)\end{array}$ & $\begin{array}{c}\text { Abs/ } \\
\mu \mathrm{m}\end{array}$ \\
\hline Poly(hydroxystyrene)(PHS) & 165 & 7.13 \\
\hline Poly(HFIPSty) & 123 & 3.25 \\
\hline Poly(HFIPA) & 30 & 4.87 \\
\hline $\begin{array}{c}\text { Poly(HFIPstyrene-co-HS) } \\
(59: 41)\end{array}$ & 107 & 4.59 \\
\hline Poly(HFIPSty-co-HS) (66:34) & 112 & 4.49 \\
\hline Poly(HS-co-HFIPA)(67:33) & 99 & 6.18 \\
\hline
\end{tabular}

We next modified certain PHS-based polymers and copolymers to study the influence of blocking group structure on absorbance at $157 \mathrm{~nm}$. The acetal-derived polymers were formed by reacting the HSbased polymers with tertiary-butyl vinyl ether (t-BVE) and an alcohol as described previously [16]. The procedure is depicted in Scheme 1:

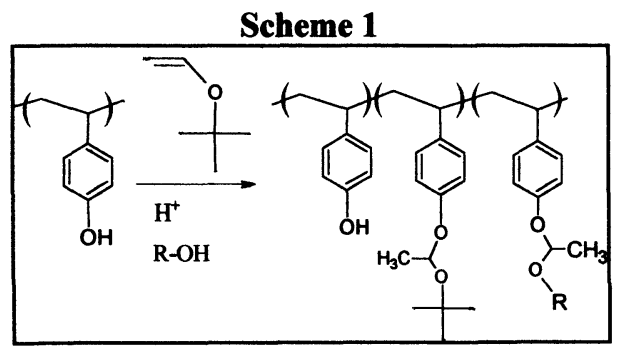

The acetal functional groups used in this study are shown in Table 2 . The choice of alcohol was made on the basis of their boiling points and anticipated contribution of their corresponding acetal to absorbance at $157 \mathrm{~nm}$. The choice of silicon-substituent was based on bilayer resist requirements.

Table 2

Structures of R-Acetal Functionalities Included in the Study

\begin{tabular}{|c|c|}
\hline (cyclohexylethyl) \\
\hline $\begin{array}{c}\mathbf{C H}_{3} \\
-\mathbf{C}-\mathbf{C H}_{3} \\
\mathbf{C H}_{3} \\
\text { (tertiary-butyl) }\end{array}$ & $\begin{array}{l}\mathbf{C H}_{2} \mathbf{C H}_{2}\left(\mathbf{C F}_{2}\right)_{5} \mathbf{C F}_{3} \\
\text { (tridecafluoro-1- } \\
\text { octanol) (fluoroalkyl) }\end{array}$ \\
\hline \multicolumn{2}{|c|}{ (Silicon-derivative) } \\
\hline
\end{tabular}

The composition and absorbance of the corresponding acetal-derivatized PHS polymers are provided in Table 3. The hydroxyl groups in each polymer are partially substituted by tertiarybutyl acetal and R-acetal groups. These results indicate that reduction in absorbance is determined by the degree of substitution and structure of the acetal.

Table 3

$157 \mathrm{~nm}$ absorbance data of PHS-based acetals

\begin{tabular}{|c|c|c|c|}
\hline R-acetal & $\begin{array}{r}\% \text { R- } \\
\text { acetal }\end{array}$ & $\begin{array}{c}\% \text { t- } \\
\text { butyl } \\
\text { acetal }\end{array}$ & $\begin{array}{c}\text { Abs/ } \\
\mu_{m}\end{array}$ \\
\hline 2-cyclohexyl-ethanol & 20 & 4 & 6.22 \\
\hline 1-naphthalene methyl & 13 & 2 & 7.51 \\
\hline fluoroalkyl & 11 & 18 & 6.82 \\
\hline silicon-derivative & 19 & 10 & 5.91 \\
\hline
\end{tabular}

The absorbance of the individual acetalblocked HS monomer unit was calculated by Beer's law. We assume that absorbance of the copolymer at $157 \mathrm{~nm}$ is the sum total of the absorbance of the individual monomer units and that there is no interaction between different 
monomer units. Hence, absorbance of a tertiarybutyl acetal blocked HS can be calculated from the equation:

$$
A_{(\text {copolymer })}=x \cdot A_{(t-b u t y l-a c e t a l)}+y \cdot A_{(H S)}
$$

where $\mathrm{x}$ and $\mathrm{y}$ are the mole fractions of each unit in the copolymer. Molar absorbances of copolymer (A (copolymer) and PHS (A (HS) are determined experimentally enabling calculation of the t-butyl acetal blocked HS moiety. In the same fashion, absorbance of the R-acetal blocked HS can be calculated from the equation:

$$
\mathrm{A}_{\text {(copolymer) }}=\mathrm{x} \cdot \mathrm{A}_{(\mathrm{t}-\text { butyl-acetal })}+\mathrm{y} \cdot \mathrm{A}_{(\mathrm{R}-\text { acetal })}+\mathrm{z} \cdot \mathrm{A}_{(\mathrm{HS})}
$$

where $x, y$, and $z$ are the mole fractions of the respective components.

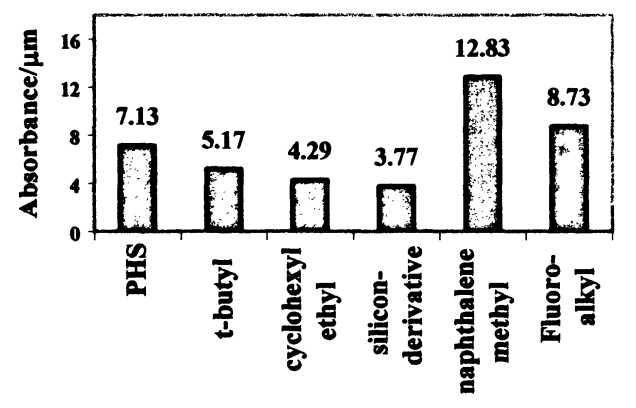

Figure 1: $157 \mathrm{~nm}$-absorbance values of various acetal groups.

The results in Figure 1 indicate that the effectiveness of the acetal groups in our study that lowered optical density follows the order of silicon-derivative $>$ cyclohexylethyl $>$ t-butyl. The acetals based on fluoroalkyl and naphthalene methyl groups showed higher absorbance than PHS. The lowest absorbance is observed in the silicon-derivative group.

The different absorbance values for the individual acetal groups are reflected in the absorbance of the corresponding PHS-acetals in Table 3. All non-silicon containing polymers absorb too strongly to be considered suitable for a single layer resist where a minimum film thickness of $2500 \AA$ is required to meet most of the plasma etching conditions.
The Si-acetal polymer, on the other hand, has an optical density enabling acceptable imaging at film thicknesses of 750 to $1500 \AA$, which is adequate for bilayer resist application. Diluting the PHS polymer backbone with more transparent, fluorinated units is an effective means of lowering the overall polymer absorbance. The optical density for one such copolymer blocked with 10 mole\% of silicon-acetal is $4.0 \mu \mathrm{m}^{-1}$ (Table 4).

Table 4

$157 \mathrm{~nm}$ absorbance data of Poly(HS-based copolymer) silicon-acetal

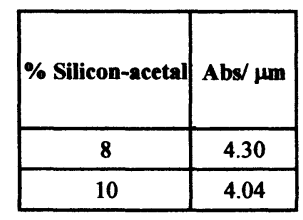

\subsection{Film shrinkage characteristics of bulky acetals}

Photoresist film shrinkage is caused by the mass/volume loss due to volatilization of the byproducts of the deprotection reaction [18].

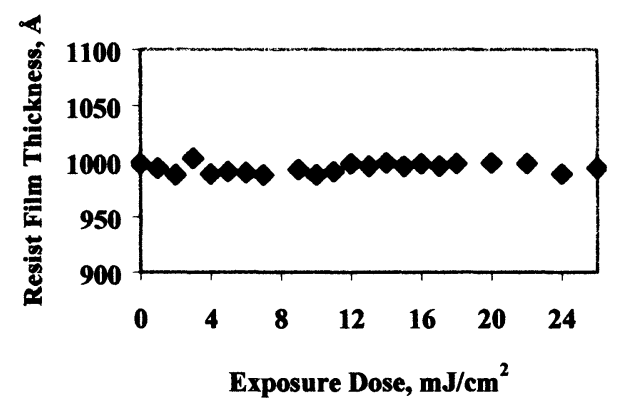

Figure 2: Film shrinkage data on silicon-acetal based resist

Figure 2 shows the changes in film thickness for the silicon-acetal as a function of exposure dose prior to bake and develop steps. As seen with other bulky acetals, this resist only loses a maximum of $1 \%$ of the original film thickness over the dose range studied. The film shrinkage of this "bulky" acetal is insignificant compared to around $11 \%$ film loss for the tertiary-butyl-acetal based resist, as reported earlier [16].

XPS-data generated on the silicon-acetal resist at International SEMATECH, using the technique 
described by Hien et al. [19], showed no silicon outgassing upon exposure at $157 \mathrm{~nm}$.

The low film shrinkage for the silicon-acetal based resist correlates with the low volatility of the corresponding alcohol, generated upon exposure.

Given the concerns that have been raised regarding the contamination of the optics of exposure tools by volatile by-products, this demonstration of minimal film loss and no silicon outgassing is encouraging.

\subsection{Lithographic performance of Si-acetal based bilayer resist:}

The results in Figure 3 show the resolution capability of the bilayer resist at a film thickness of $750 \AA$ of imaging layer over $800 \AA$ of DUV 30 . $130 \mathrm{~nm}$ dense trench patterns could be printed at an exposure dose of $15.5 \mathrm{~mJ} / \mathrm{cm}^{2}$ with an ultimate resolution of $80 \mathrm{~nm}$.

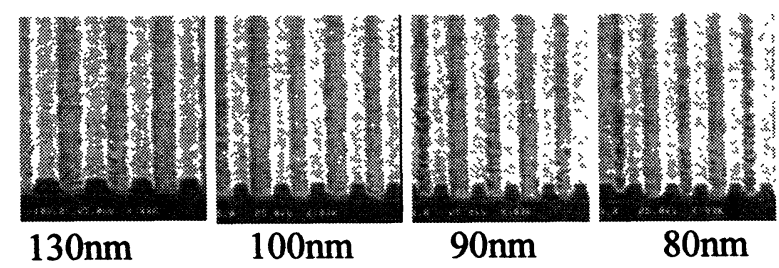

Figure 3: Dense trench patterns printed into $750 \AA$ of silicon- resist (Exitech exposure tool; NA: 0.65; sigma: 0.3 ; alternating-PSM)

\subsection{Etch characteristics of Si-acetal based bilayer resist:}

Figure 4 shows the etch rates obtained from silicon-acetals at varying silicon content. Under the etching conditions chosen, acceptable rates can be obtained with silicon content greater than about $7 \%$. Results are comparable to those obtained with TIS2000.

Figure 5 shows $150 \mathrm{~nm}$ dense line-space patterns transferred into $5000 \AA$ of an underlayer designed specifically for $248 \mathrm{~nm}$ bilayer application [20]. Excellent etch selectivity between silicon-containing imaging layer and thermally cured underlayer is attested to by the fact that about $20 \%$ of the original film thickness $(2350 \AA)$ of imaging layer was left after etching through $5000 \AA$ of underlayer.

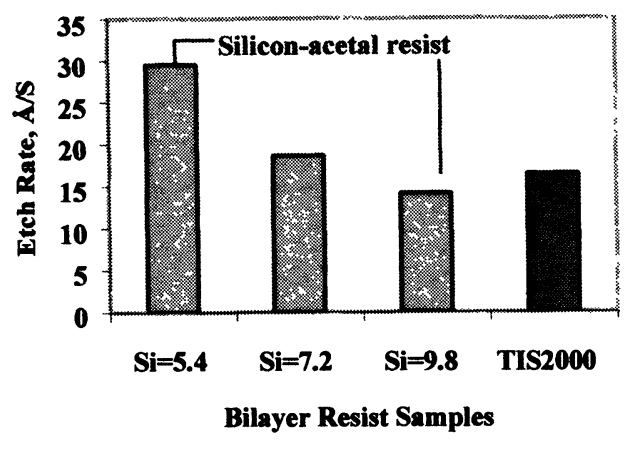

Figure 4: Comparison of blanket etch rates of silicon-acetal resist at various Si-levels

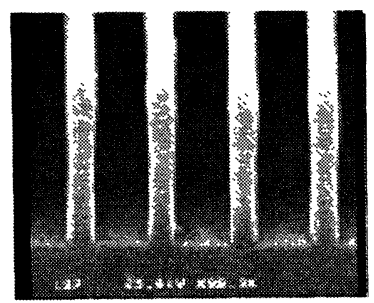

Figure 5: 150nm dense line-space patterns etched into $5000 \AA$ of an organic underlayer

\section{Conclusions:}

Partial substitution of the hydroxyl groups of HS based polymers with certain acetals lowers their absorbance at $157 \mathrm{~nm}$. The effectiveness of an acetal group in lowering optical density follows the order of silicon-derivative > cyclohexylethyl > t-butyl. Fluoroalkyl- and naphthalene methylacetals increase molar absorbance of the backbone. Dilution of PHS with certain fluorinated monomers further improves optical absorbance of the polymer backbone.

With proper design, silicon-derivatized polymer can be obtained with optical density suitable for a bilayer resist application. The silicon-acetal resist does not show any silicon outgassing upon exposure at $157 \mathrm{~nm}$. The resist has demonstrated resolution of $80 \mathrm{~nm}$ at a reasonable photospeed. Etch properties of the resist can be tuned by optimizing the silicon content

\section{Acknowledgements:}

We would like to acknowledge the support of Kim Dean and the staff at International SEMATECH for generating silicon-out-gassing and lithographic data. 


\section{References:}

1. International Technology Roadmap for Semiconductors, 1999 Edition, International SEMATECH (1999).

2. M. Rothchild, T. M. Bloomstein, T. H. Fedynyshyn, R. R. Kunz, V. Liberman, and M. Switkes, J. Photopolymer Sci. and Technol., 13 (3), (2000), 369.

3. H. Ito, G. M. Wallraff, P. Brock, N. Fender, H. Truong, G. Breyta, D. C. Miller, M. H. Sherwood, and R. D. Allen, Proceedings, SPIE, 4345, (2001) 273.

4. R. R. Kunz, T. M. Bloomstein, D. E. Hardy, R. B. Goodman, D. K. Downs and J. E. Curtin, Proceedings SPIE, 3678, (1999) 13.

5. T. M. Bloomstein, M. W. Horn, M. Rothchild, R. R. Kunz, D. E. Hardy, R. B. Goodman, and S. T. Palmacci, J. Vac. Sci. Technol., B16, (1998) 3154

6. M. K. Crawford, A. E. Feiring, J. Feldman, R. H. French, M. Periyasamy, F. I. Schadt III, R. J. Smalley, F. C. Zumsteg, R. R. Kunz, V. Rao, L. Liao, S. M. Holl, Proceedings SPIE, 3999, (2000) 357.

7. M. K. Crawford, A. E. Feiring, J. Feldman, R. H. French, V. Petrov, F. L. Schadt III, R. J. Smalley, and F. C. Zumsteg, Proceedings SPIE, 4345, 428 (2001), 357.

8. R. Sooriyakumaran, D. Fenzel-Alexander, N. Fender, G. M. Wallraff and R. D. Allen, Proceedings SPIE, 4345, (2001) 319.

9. K. Patterson, M. Yamachika, R. Hung, C. Brodsky, S. Yamada, M. Somervell, B. Osborn, D. Hall, G. Dukovic, J. Byers, W. Conley, and C. G. Willson, Proceedings SPIE 3999, (2000) 365.

10. T. Chiba, R. J. Hung, S. Yamada, B. Trinque, M. Yamachika, C. Brodsky, K. Patterson, A. Van der Heyden. A. Jamison, S.-H. Lin, M. Sommervell, J. Byers, W. Conley, and C. J. Willson, J. Photopolymer Sci. Technol., 13, (2000) 657.
11. H. V. Tran, R. J. Hung, T. Chiba, S. Yamada, T. Mrozek, Y.T. Hsieh, C. R. Chambers, B. P. Osborn, B. C. Trinque, M. J. Pinnow, D. P. Sanders, E. F. Connor, R. H. Grubbs, W. Conley, S. A. MacDonald, C. G. Willson., $J$. Polymer Sci., and Technol., 144 (4), (2001) 669.

12. Y. C. Bae, K. Douki, T. Yu, J. Dai, D. Schmaljohann, S. Kang, K. Kim, H. Koerner, W. Conley, D. Miller, R. Balasubramanain, S. Holl, and C. K. Ober, J. Photopolymer Sci., 14 (4), (2001) 613.

13. R. Kunz., R. Sinta, M. Sworin, W. A. Mowers, T. H. Fedynyshyn, V. Liberman and J. E. Curtin, Proceedings SPIE, 4345, (2001) 285.

14. N. Fender, P. J. Brock, W. Chau, S. Bangsaruntip, A. Mahorowala, G. M. Wallraff, W. D. Hinsberg, C. E. Larson, H. Ito, G. Breyta, K. Burnham, H. Truong, P. Lawson and R. D. Allen, Proceedings SPIE, 4345, (2001) 417.

15. T. Fedynyshyn, R. R. Kunz, R. F. Sinta, M. Sworin, W. A. Mowers, R. B. Goodman, and S. P. Doran, Proceedings SPIE, 4345, (2001) 296.

16. S. Malik, A. J. Blakeney, L. Ferreira, J. Sizensky, B. Maxwell, T. Kocab, T. R. Sarubbi, B. A. Blachowicz, M. J. Bowden, $J$. Photopolym. Sci. Technol., 11 (3), (1998) 431; US Patent Nos. 6380317, 6159653 and 6133412.

17. M. J. Bowden, S. Malik, L. Ferreira, J. Eisele, A. Whewell, T. Kokubo, Y. Kawabe, T. Fujimori, S. Tan, J. Photopolym. Sci. Technol., 13 (4), (2000) 507.

18. P.J. Paniez and L. Pain, J. Vac.Sci.Technol., V8, (1993) 643

19. S. Hein, S. Angood, D. Ashworth, S. Basset, T. Bloomstein, K. Dean, R.R. Kunz, D. Miller, S. Patel and G. Rich, Proc. SPIE, Adv. Resist Tecnol. Process, XVIII, 4345 (2001) 439.

20. S. Malik, B. De, J. Biafore, G. Spaziano, T. Sarubbi, S. Dilocker, M. Bowden, $J$. Photopolym. Sci. Technol., 14 (3), (2001) 489. 